\title{
Wear and Friction Behavior of Pressure Infiltration Cast Copper- Carbon Composites
}

\author{
G. Göller \\ Istanbul Technical University \\ D. P. Koty \\ Cleveland State University
}

M. Singh

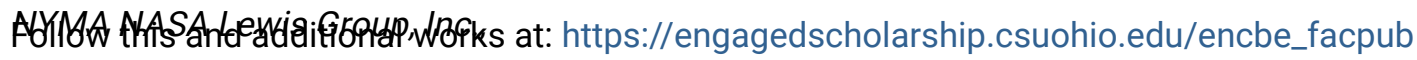

Treatrinof the Chemical Engineering Commons

istankyb Eschnical Univirisity

Publisher's Statement

This is the accepted version of the following article: Göller, G., Koty, D. P., Tewari, S. N., Singh, M., , \& Tekin, A. (2001). Wear and friction behavior of pressure infiltration cast copper-carbon composites. Scandinavian Journal of Metallurgy, 30(2), 77-83., which has been published in final form at http://onlinelibrary.wiley.com/doi/10.1034/j.1600-0692.2001.300204.x/abstract

\section{Original Citation}

Göller, G., Koty, D. P., Tewari, S. N., Singh, M., , \& Tekin, A. (2001). Wear and friction behavior of pressure infiltration cast copper-carbon composites. Scandinavian Journal of Metallurgy, 30(2), 77-83.

doi:10.1034/j.1600-0692.2001.300204.x

\section{Repository Citation}

Göller, G.; Koty, D. P.; Singh, M.; and Tekin, A., "Wear and Friction Behavior of Pressure Infiltration Cast CopperCarbon Composites" (2001). Chemical \& Biomedical Engineering Faculty Publications. 44.

https://engagedscholarship.csuohio.edu/encbe_facpub/44

This Article is brought to you for free and open access by the Chemical \& Biomedical Engineering Department at EngagedScholarship@CSU. It has been accepted for inclusion in Chemical \& Biomedical Engineering Faculty Publications by an authorized administrator of EngagedScholarship@CSU. For more information, please contact library.es@csuohio.edu. 


\title{
Wear and Friction Behavior of Metal Impregnated Microporous Carbon Composites
}

\author{
GULTEKIN GOLLER, D.P. KOTY, S.N. TEWARI, M. SINGH, and A. TEKIN
}

Metal-matrix composites have been prepared by pressure-infiltratio casting of copper-base alloy melts into microporous carbon preforms. The carbon preforms contained varying proportions of amorphous carbon and graphite. Load dependence of the wear and friction behavior of the composite pins has been examined under ambient conditions against cast-iron plates, using a pin-on-plate reciprocating wear tester. The wear resistance of the composite is significantl improved, as compared with the base alloy. Contrary to the normally expected behavior, the addition of graphite to the amorphous carbon does not reduce the friction coefficient especially at high loads. The wear and friction behavior of the composites is very sensitive to the size and distribution of the microstructural constituents.

\section{INTRODUCTION}

Metal-MATRIX composites, reinforced by nonmetallic fibers whiskers, and particulates, are being seriously examined for structural, thermal-management, and wear applications. Copper matrix-carbon composites are specially suited for thermal-management applications, because of their low coefficien of thermal expansion, high thermal conductivity, and low density. ${ }^{[1]}$ They are also attractive for wear applications, such as sliding electrical contacts, bearings, and bushings..$^{[2]}$ Solid-state consolidation techniques, such as sintering ${ }^{[3]}$ and hot pressing, ${ }^{[4]}$ and casting processes, ${ }^{\left[{ }^{[}\right]}$have been used to prepare these composites. However, the casting techniques, such as stir casting, ${ }_{,}^{[6]}$ compocasting, ${ }^{[7]}$ and various forms of melt infiltration ${ }^{[8]}$ are more attractive because of their net shape capability and low processing cost. For the most part, graphitic carbon has been used for copper matrix-carbon composites in wear applications, because its addition (graphite-particle volume fraction $>0.2)^{[2]}$ reduces the coefficien of friction and increases the wear resistance, as compared with the matrix. Easy glide of the basal planes under ambient conditions is responsible for the lubricity and antiseizure characteristics of graphite. Glassy (amorphous) carbon, on the other hand, is much harder, about 8 Moh. ${ }^{\left[{ }^{[]}\right.}$One would, therefore, expect a higher strength and wear resistance from a copperalloy composite containing glassy carbon. There is only one study on copper-amorphous carbon composite, ${ }^{[9]}$ where copper wires (30 to $50 \mu \mathrm{m}$ in diameter) were introduced into an organic material, after which polymerization and pyrolysis yielded a glassy carbon matrix. This composite

GULTEKIN GOLLER, formerly UNIDO Fellow, Chemical Engineering Department, Cleveland State University, is Graduate Student with the Department of Materials Science, Istanbul Technical University, Istanbul, Turkey. D.P. KOTY, formerly Graduate Student, Chemical Engineering Department, Cleveland State University, is with Applied Materials, 3100 S. Vista Ave., Suite 140, Boise, ID 83705. S.N. TEWARI, Professor, is with the Chemical Engineering Department, Cleveland State University, Cleveland, OH 44115. M. SINGH, Senior Research Engineer, is with NYMA Inc., NASA-Lewis Research Center Group, Cleveland, OH 44135. A TEKIN, Professor, is with the Department of Materials Science, Istanbul Technical University, Istanbul, Turkey.

Manuscript submitted March 22, 1996. showed low wear rates and friction coefficients comparable to those typically observed in graphite and copper matrixgraphite composites. Graphite sliding against itself yields a low coefficien of friction, about 0.1 , independent of the sliding distance, but the friction coefficien between two amorphous carbon surfaces increases from 0.1 to a steadystate value of about $0.8 \cdot{ }^{[10]}$ Intuitively, one would therefore expect that metal-matrix composites containing amorphous carbon would show similar high friction coefficients However, the observed behavior is to the contrary. The copper fiber-reinforce amorphous carbon yielded a low and constant coefficien of friction, about 0.16 , independent of sliding distance. ${ }^{[9]}$ The role of graphitic $v s$ amorphous carbon in the metal-matrix composites in determining their friction and wear behavior is not understood.

The purpose of this research was to develop copper matrix-carbon composites by melt infiltratio into microporous carbon preforms, containing different volume fractions of amorphous and graphitic carbon, and study their wear and tribological behavior against cast-iron plates under ambient conditions. Microporous carbon preforms ${ }^{[11,12]}$ were selected instead of the conventionally used carbon particulates, ${ }^{[2]}$ because their melt infiltratio was expected to result in a fin and uniform distribution of the two phases, metallic matrix and carbon. Such a fin distribution would be expected to yield improved mechanical properties and wear resistance. The $\mathrm{Cu}-6 \mathrm{Si}-0.9 \mathrm{Cr}$ alloy was selected as the matrix because of the high thermal conductivity and heat capacity of copper, improved wettability between the copper melt and carbon due to the addition of chromium, ${ }^{[13]}$ increased fluidit due to the addition of silicon, and the expected improvement in the wear resistance due to the presence of silicon and chromium-carbide particulates.

\section{EXPERIMENTAL PROCEDURE}

\section{A. Preform Fabrication}

The microporous carbon preforms were made from a mixture of furfural alcohol resin, diethylene and triethylene glycol, and $p$-toluene sulfonic acid. ${ }^{[12]}$ The mixture was polymerized to form a porous solid polymer, which is heated up to $973 \mathrm{~K}$ to yield porous amorphous carbon preform. 


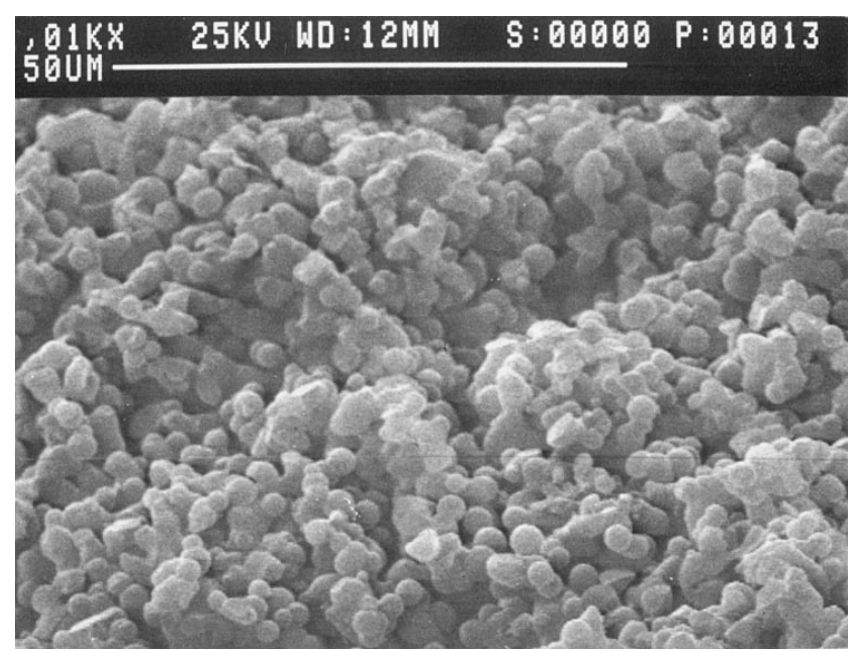

(a)

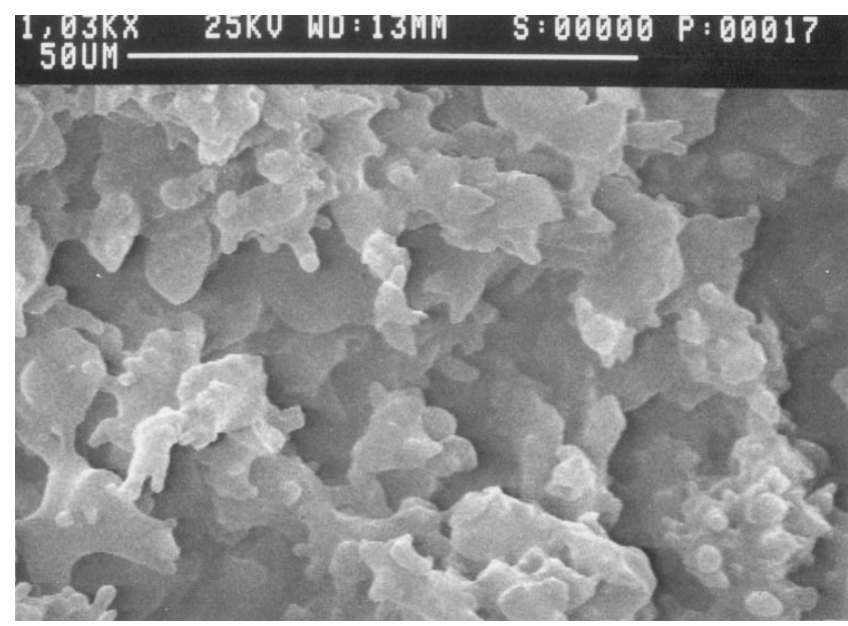

(b)

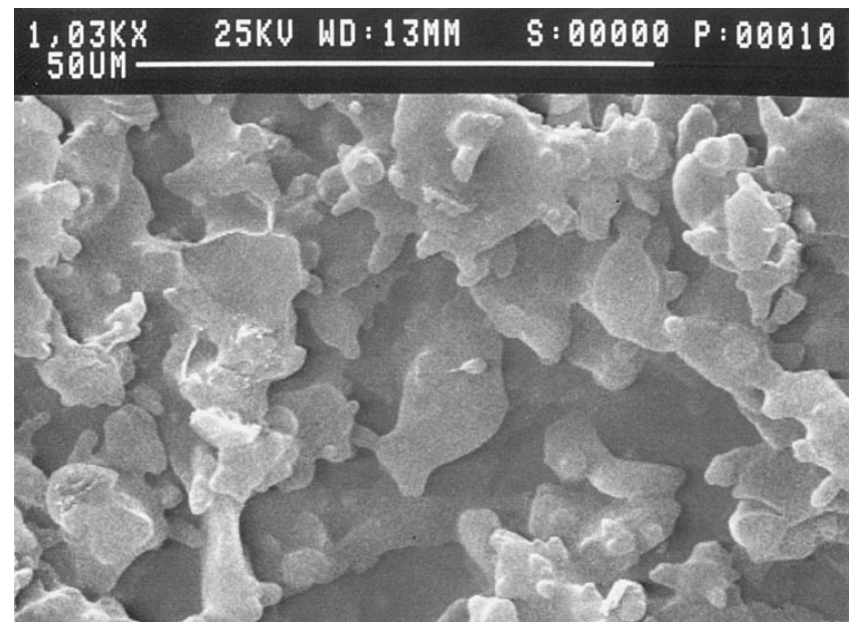

(c)

Fig. 1-Typical SEM image of microporous carbon preforms: (a) type $1-100$ pct amorphous carbon; (b) type $2-20$ pct graphite particulates and the remainder amorphous carbon; and (c) type 3-40 pct graphite and 60 pet amorphous carbon.

Graphite particulates ( -440 mesh) were mixed into the aforementioned liquid mixture to yield varying proportions of amorphous vs graphitic carbon in the porous preforms.
Mercury porosimetry was used to characterize the pore size distribution of the preform.

\section{B. Melt Infiltratio}

The $\mathrm{Cu}-6 \mathrm{Si}-0.9 \mathrm{Cr}$ (by weight percent) alloy ingots were prepared by induction melting the charge in an alumina crucible under a flowin UHP argon atmosphere. This alloy has a liquidus of $1129 \mathrm{~K}$. The alloy was remelted in a pressure-infiltratio casting facility and was pushed upward into cylindrical microporous preforms $(0.6-\mathrm{cm}$ diameter, $10-\mathrm{cm}$ long) kept in an alumina tube by the help of 500 psi argon pressure. The pressure-infiltratio casting facility provided independent control of the melt and preform temperatures in order to achieve successful infiltration

\section{Wear and Friction Behavior}

Wear and friction experiments were carried out in a pinon-plate reciprocating wear tester ${ }^{[14]}$ under ambient conditions at room temperature. Composite pins $(0.6-\mathrm{cm}$ diameter, 2.2-cm long) were tested against cast iron (wear track length $=4 \mathrm{~cm}$ ). The load, ranging from 4 to $30 \mathrm{~kg}$, was applied on the composite pin, rubbing against the reciprocating plate (constant linear speed $20 \mathrm{~cm} \mathrm{~s}^{-1}$ ). The friction force and pin displacements, measured by transducers, were recorded with the help of a Hewlett-Packard*

*HEWLETT-PACKARD is a trademark of Hewlett-Packard Company, Colorado Springs, CO.

data acquisition unit. Because of the reciprocating motion involved, the plate and the pin came to rest at the end of each cycle, and the rod impacting on the friction force transducer vibrated vigorously. Therefore, a triggering arrangement was used to stop the data acquisition near the end of the cycle, to prevent collecting these erratic data. The time for each run, 90 minutes, and all other variables were kept constant.

\section{RESULTS}

\section{A. Microstructure}

\section{Preform}

Figure 1 shows typical microstructures of the three types of microporous carbon preforms examined in this study. The "type 1' contains only amorphous carbon (Figure 1(a)), 'type 2', contains 20 vol pct graphite particulates (Figure 1(b)), and "type 3" contains 40 pct graphite and 60 pct amorphous carbon (Figure 1(c)). The carbon struts and the interconnected continuous porosity can be clearly seen in these scanning electron micrographs. Addition of graphite particles has resulted in significan increase in the pore sizes, for otherwise identical processing conditions. The pore size distributions, obtained by mercury porosimetry, are presented in Figure 2 for type 1 preform, which has a median pore diameter (volume) of $1.68 \mu \mathrm{m}$, average pore diameter of $0.10 \mu \mathrm{m}$, fraction porosity of 0.48 , bulk density of $0.77 \mathrm{~g} \mathrm{~cm}^{-3}$, and skeletal density of $1.48 \mathrm{~g} \mathrm{~cm}^{-3}$. For the type 1 preform, the skeletal density measured by mercury porosimetry, $1.48 \mathrm{~g} \mathrm{~cm}^{-3}$, is in close agreement with the density of amorphous carbon, $1.5 \mathrm{~g} \mathrm{~cm}^{-3}$, indicating the continuity of pores (in the presence of isolated pores the skeletal density would appear to be less than the 


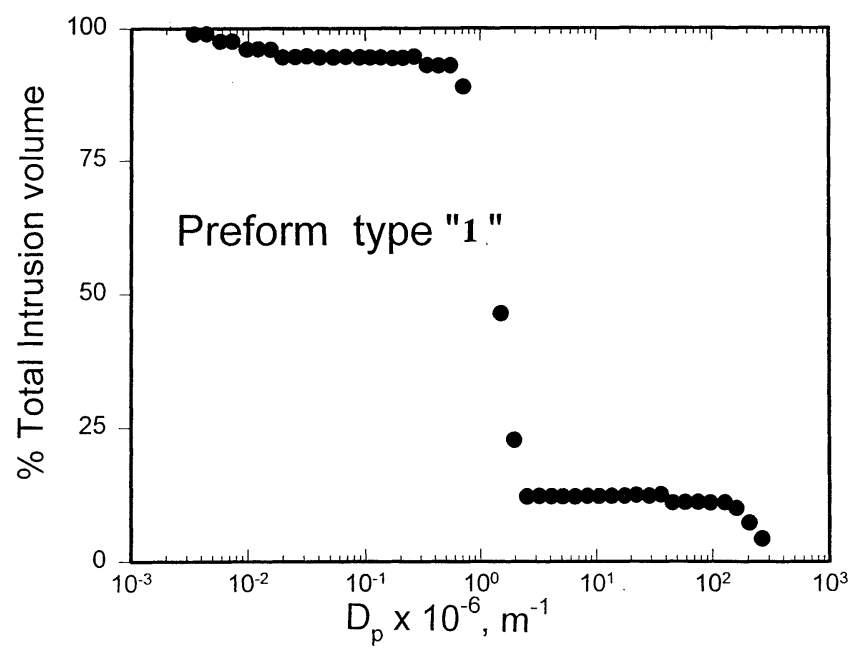

Fig. 2-Pore size distributions for type $1-100$ pct amorphous carbon preform obtained by mercury porosimetry.

true density of the amorphous carbon). Addition of graphite has resulted in increased pore sizes.

\section{Composite}

Typical microstructures of the three infiltratio cast composites are presented in Figure 3. In these micrographs, the light regions are the copper-alloy matrix and the gray regions are the amorphous carbon. Both the uninfiltrate pores and graphite particles (typically marked by arrows) appear dark. Both constituents in the microstructure, the carbon and the metallic phase, are much fine in the type 1 (Figure 3(a)), as compared with the type 2 (Figure 3(b)) and type 3 (Figure 3(c)) composites. Increasing the volume fraction of graphite particles also resulted in more uninfil trated regions in the vicinity of the graphite particles (compare Figure 3(a) with (b) and (c)). Agglomeration of the graphite particles was not observed. However, amorphous carbon appears to nucleate on the preexisting graphite particles, and produce isolated pores in their vicinity that do not get infiltrate by the copper-alloy melt. Volume fractions of carbon struts, alloy matrix, infiltrate porosity, and average distance between the carbon struts were determined with the help of quantitative image analysis of the optical microcopy images (Table I).

\section{Reaction between Melt and Preform}

Figure 4 shows low-magnificatio views of the infiltra tion cast composite, based on the type 1 preform. In Figure 4(a), the bright outside shell contains copper-alloy matrix, and corresponds to the gap between the inner surface of the alumina mold $(0.6-\mathrm{cm}$ ID) and the periphery of the porous preform, through which the melt firs infiltrated The infil tration, therefore, occurs both from the bottom and the side of the preforms. The composite interior consists of two finel distributed phases, the bright-looking copper-alloy matrix and the dark-looking carbon struts.

A closer examination of the composite near the copperalloy shell showed existence of a 50 - $\mu \mathrm{m}$-thick chromiumrich layer. A backscattered scanning electron image and the corresponding chromium X-ray map for this region are shown in Figures 4(b) and (c), respectively. In these figures the bottom portions correspond to the copper-alloy shell at the periphery, and the top portions to the composite interior.

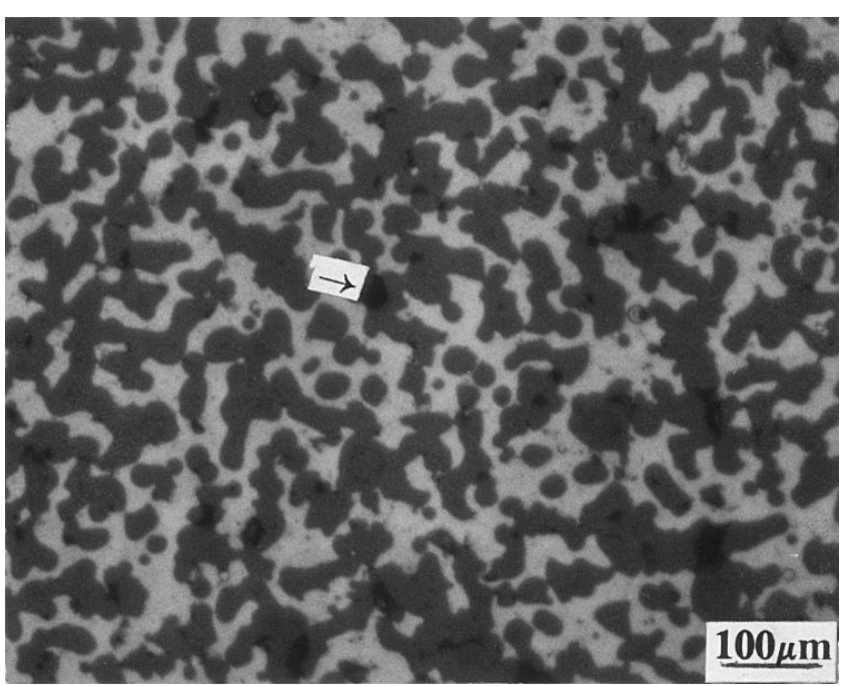

(a)

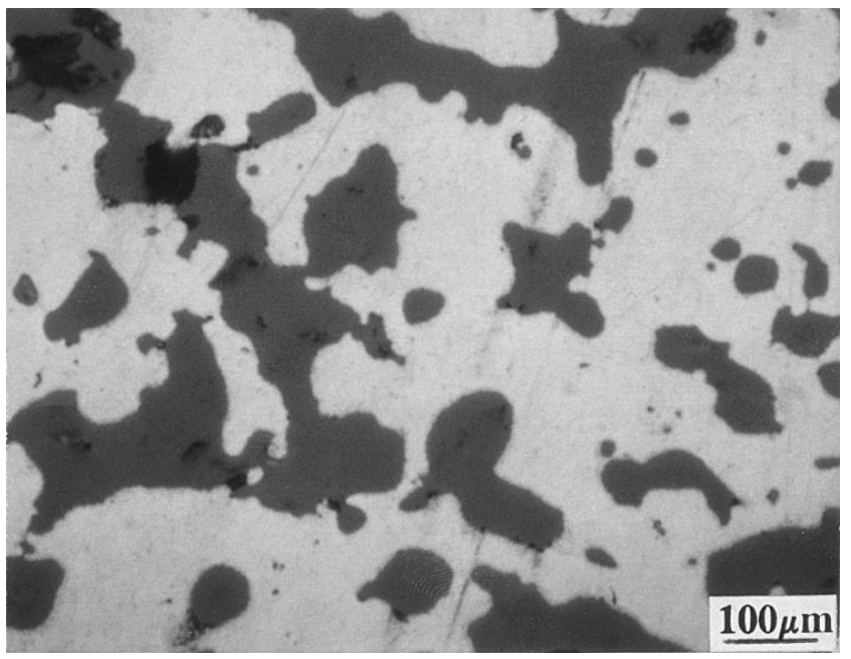

(b)

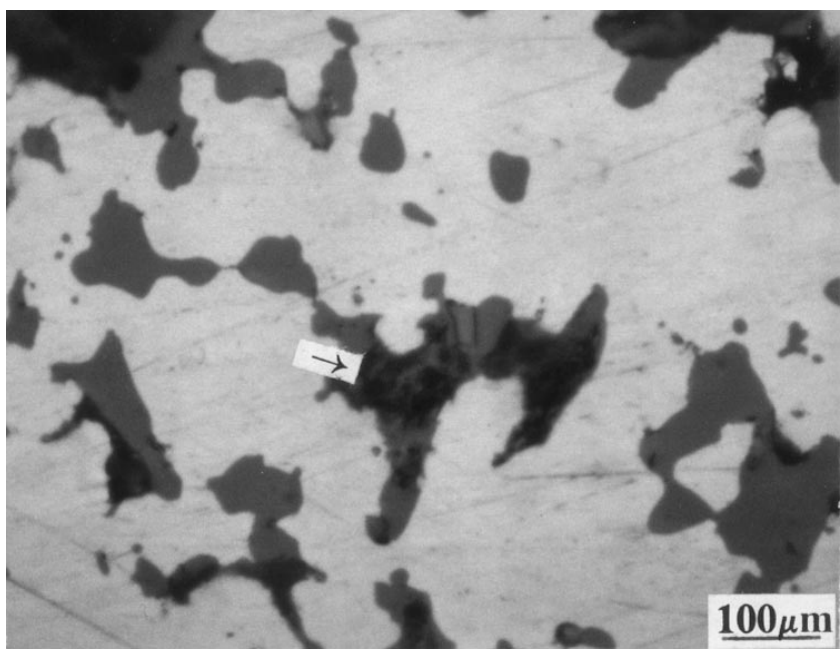

(c)

Fig. 3-Typical microstructures of the infiltratio cast composites: $(a)$ type 1-composite based on amorphous carbon preform; (b) type 2composite based on 20 pct graphite +80 pct amorphous carbon preform; and $(c)$ type 3 - composite based on 40 pct graphite +60 pct amorphous carbon preform. 
Table I. Microstructural Characterization of Pressure Infiltrate Copper Carbon Composite

\begin{tabular}{lcccc}
\hline Preform & $\begin{array}{c}\text { Matrix } \\
\text { Volume } \\
\text { Fraction }\end{array}$ & $\begin{array}{c}\text { Carbon Strut } \\
\text { Volume } \\
\text { Fraction }\end{array}$ & $\begin{array}{c}\text { Porosity } \\
\text { Volume } \\
\text { Fraction }\end{array}$ & $\begin{array}{c}\text { Average Distance } \\
\text { Between Struts } \\
(\mu \mathrm{m})\end{array}$ \\
\hline Type 1 & 0.43 & 0.50 & 0.07 & 12 \\
Type 2 & 0.48 & 0.43 & 0.09 & 83 \\
Type 3 & 0.67 & 0.24 & 0.09 & 59 \\
\hline
\end{tabular}

Apparently, most of the chromium in the melt simply concentrated in this thin outer layer of the composite, with little getting into the preform interior.

High-magnificatio scanning electron images, and the energy-dispersive spectra from the composite interior and the exterior reaction zone, are shown, respectively, in Figures 5(a) and (b). The copper-alloy matrix (bright phase) and the carbon struts (black phase) are present in the composite interior (scanning electron microscope (SEM) image in Figure 5(a)). In addition, there appears to be some very fin precipitates within the carbon struts, near their surface. The microstructure within the $50-\mu \mathrm{m}$-thick reaction layer (SEM image in Figure 5(b)) is very different from that in the composite interior. This region contains a large volume fraction of a gray phase, surrounding the carbon struts and also precipitating within the carbon struts. The spectra presented in the inset are taken from the alloy matrix, the carbon strut, and from the light-gray phase. The matrix, both in the interior and in the 50- $\mu \mathrm{m}$-thick reaction layer, contains only copper and silicon (the left-most spectra in the insets in Figures 5(a) and (b)). The carbon struts show mostly carbon, with some trace of sulphur (the central spectra in the insets in Figures 5(a) and (b)). Sulfur must have come from the organic constituents during pyrolysis of the preform. The light-precipitate region within the carbon struts, from the composite interior, appears to contain copper, silicon, and carbon (the right-most spectra in the inset in Figure 5(a)), suggesting them to be silicon-carbide precipitates. The light-gray continuous layer on the surface of the carbon struts within the $50-\mu \mathrm{m}$-thick external reaction layer is very rich in chromium (right-most inset of Figure 5(b)), suggesting it to be primarily made of chromium carbide.

The exact mechanism for the formation of this $50-\mu \mathrm{m}$ thick chromium carbide-rich reaction layer on the surface of the pressure-infiltratio cast composite samples is not understood. It may be related to the relative stability of the chromium carbide $v s$ silicon carbide, and their rates of formation. Apparently, the chromium in the infiltratin melt readily reacts with the carbon, thus depleting the melt before it reaches the preform interior. Also, before infiltration the preform interior is about $50 \mathrm{~K}$ below the alloy liquidus, and the melt is superheated by about $150 \mathrm{~K}$. The melt may, therefore, solidify quickly within the interior, whereas it may be in contact with the surface of the preform for a much longer time. Longer melt-carbon contact times would lead to more reaction. In any case, formation of such a hard surface layer may be desirable for some applications.

\section{Cast iron}

The pins for the wear testing were made from the composite interior, and were tested against cast-iron plates, whose typical microstructure is shown in Figure 6. It con- sists of graphite particles (about $10 \mathrm{vol}$ pct) imbedded in a fin pearlitic matrix.

\section{B. Wear and Friction of the Copper Alloy (Cu-6Si-0.9Cr)-Amorphous Carbon Composite}

\section{Wear and friction}

Figure 7 shows typical coefficien of friction and wear (contact displacement) data as a function of the sliding distance. Figure $7(\mathrm{a})$ is for the matrix alloy $(\mathrm{Cu}-\mathrm{Si}-0.9 \mathrm{Cr})$ pin against cast-iron plate. Figure 7(b) is the corresponding contact displacement data. We will use the slope of the contact displacement $v s$ sliding distance plot as an indicator of the rate of wear, because no appreciable wear was observed on the cast-iron plates examined in this research. Figure 7(c) is a typical coefficien of friction behavior for the copper matrix-amorphous carbon-composite (type 1) pin wearing against cast-iron plate. The wear conditions for the composite were identical to those used for the matrix alloy in Figure 7(a). The matrix alloy pins showed a slight increase in the coefficien of friction in the beginning, and then a steady-state constant friction coefficient For similar test conditions, the composite pin showed an initial rise in the coefficien of friction, followed by a decrease and the subsequent steady-state value.

A comparison of the initial transients is better represented in Figure 8. For the matrix alloy, there was an initial rise in the coefficien of friction irrespective of the applied load, typically shown as a circle. For the composite pin, the behavior at low stress, $7.86 \mathrm{MPa}$ (shown as triangles), is different from that at high stress, $43 \mathrm{MPa}$ (shown as squares). At low stress, the friction coefficien initially decreased from 0.22 to 0.12 for a traverse distance of about $60 \mathrm{~m}$, and then slowly (traverse distance about $750 \mathrm{~m}$ ) it increased to its steady-state value, about 0.16 . At high stress, the coefficien increased from 0.25 to about 0.43 in about $8 \mathrm{~m}$, and then rapidly (within a traverse distance of $25 \mathrm{~m}$ ) dropped to the steady-state value of about 0.21 .

Figure 9 compares the variation in the steady-state coefficien of friction with the applied normal stress for (1) the copper-alloy matrix $(\mathrm{Cu}-6 \mathrm{Si}-0.9 \mathrm{Cr})$ pin on cast-iron plate (shown as deltoids), (2) the copper alloy-amorphous carbon composite (type 1) pin on cast-iron plate (shown as triangles), and (3) the cast-iron pin on cast-iron plate (shown as circles). The coefficien of friction for the matrix alloy increased from 0.24 to about 0.37 , with the applied stress increasing from 5.9 to $47 \mathrm{MPa}$. The matrix alloy showed a significantl larger coefficien of friction, for all the load conditions examined in this study, compared to the type 1 composite pin. For the composite pins, the friction coefficient appear to be independent of the applied load, varying between 0.15 and 0.2 . The cast-iron pin on the castiron plate showed the highest coefficien of friction, about 0.7 . Lack of data for the cast-iron pin at the higher stresses is attributable to the extreme adhesive nature of the wear, which resulted in excessive machine vibration.

Figure 10 shows the extent of fluctuatio in the steadystate coefficien of friction as a function of the normal stress applied on the pin. For the copper-matrix alloy pin, not only the absolute value of the friction coefficien increased with the applied load, but the extent of its fluctuatio also increased (Figure 10(a)). For the type 1 composite, the extent of fluctuatio (Figure 10(b)) was significantl less than that 

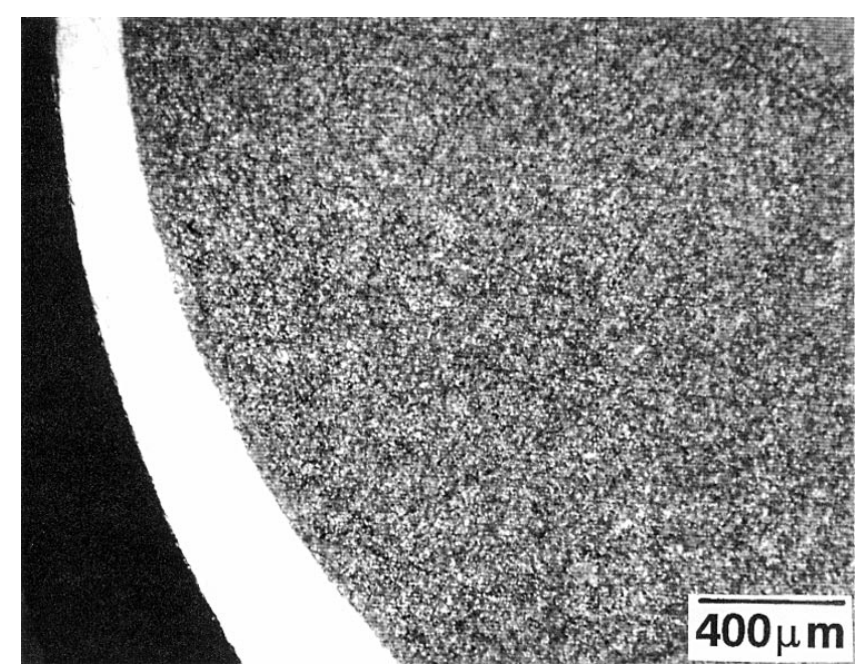

(a)

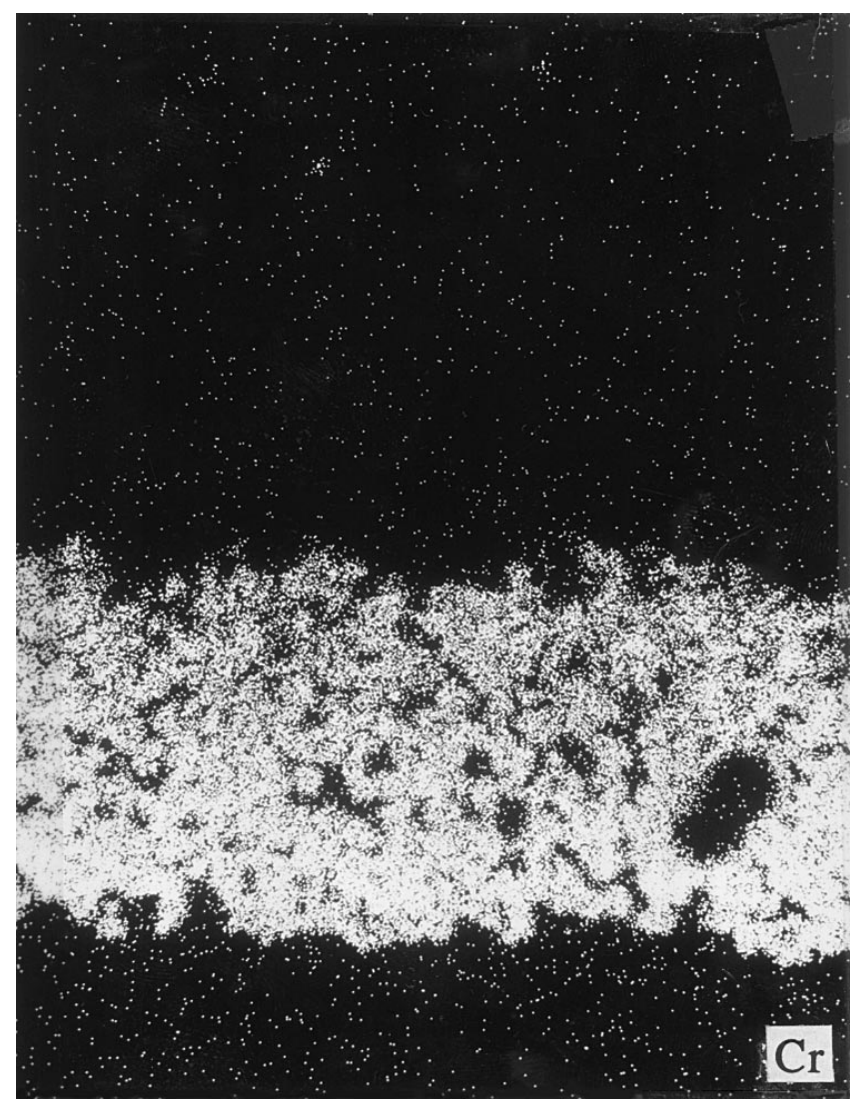

(c)

for the matrix alloy pin. In addition, the fluctuatio did not increase with the increased normal stress. Figures 10(c) and (d) correspond to the type 2 and type 3 composite pins and will be discussed later.

Figure 11 compares the dependence of the wear rates on the applied normal stress for (1) the copper-matrix alloy pin on cast-iron plate (shown as deltoids), (2) the type 1 composite pin on cast-iron plate (shown as triangles), and (3) the cast-iron pin on cast-iron plate (shown as circles). The extent of wear increases with the increasing stress for all the three types of pins. However, the extent of wear for the type 1 composite pin is about one order of magnitude

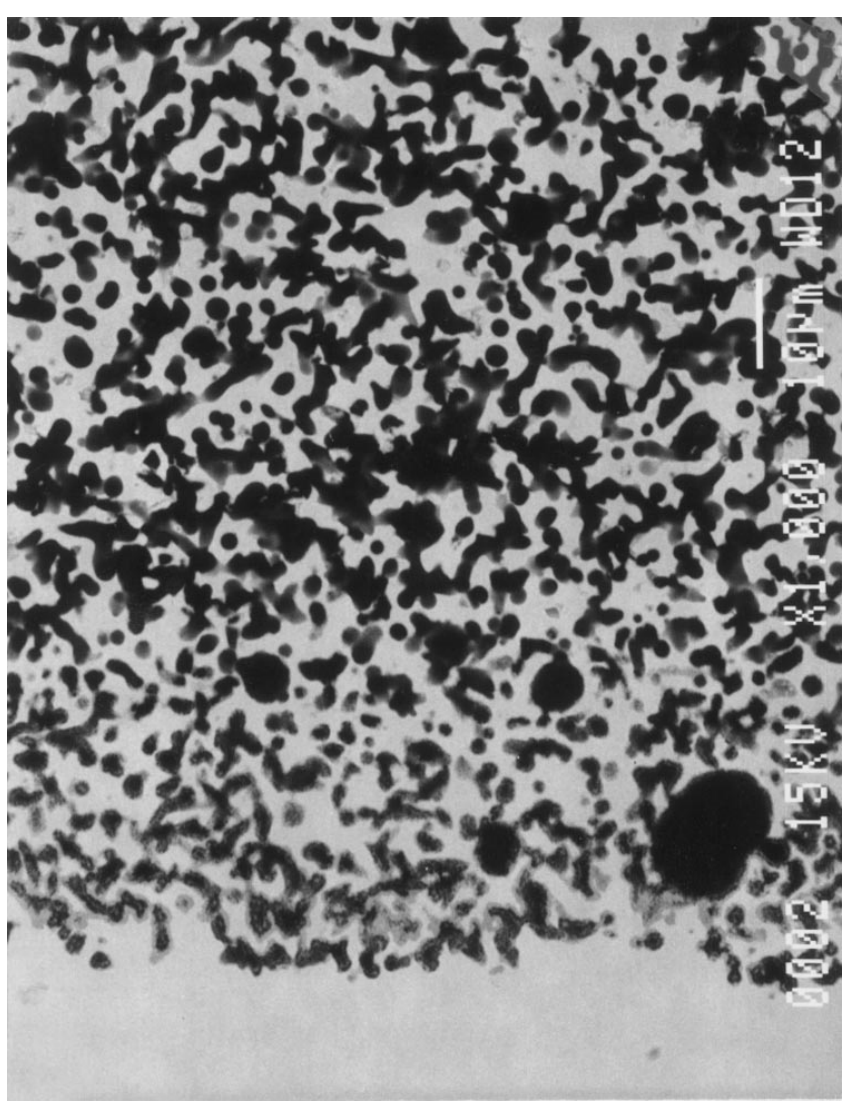

(b)

Fig. 4-Microstructure of the infiltratio cast composite based on the amorphous carbon preform. (a) A low magnificatio view of the composite. The bright metal ring corresponds to the gap between the carbon preform and the alumina tube ID. (b) Backscattered SEM image of the exterior region in the composite. The top portion is the composite interior, and the bottom portion the exterior bright metal ring of Fig. (a). (c) Chromium X-ray map corresponding to the microstructure in Fig. (b).

less than that for the matrix alloy pin. The cast-iron pin showed the highest wear.

\section{Metallography of wear surface}

Examination of the pin surface after wear (40 MPa, 20 $\mathrm{m} \mathrm{s}^{-1}$ ) showed that the matrix alloy pin (Figure 12(a)) had a significantl rougher surface than the type 1 composite pin (Figure 12(b)). The tribo-surface of the matrix alloy pin showed significan grooving and delamination, as indicated by a typical deep crater and a large piece of delaminated particle in Figure 12(a). Such a microstructure can result from repeated cold welding of the asperities on the two 


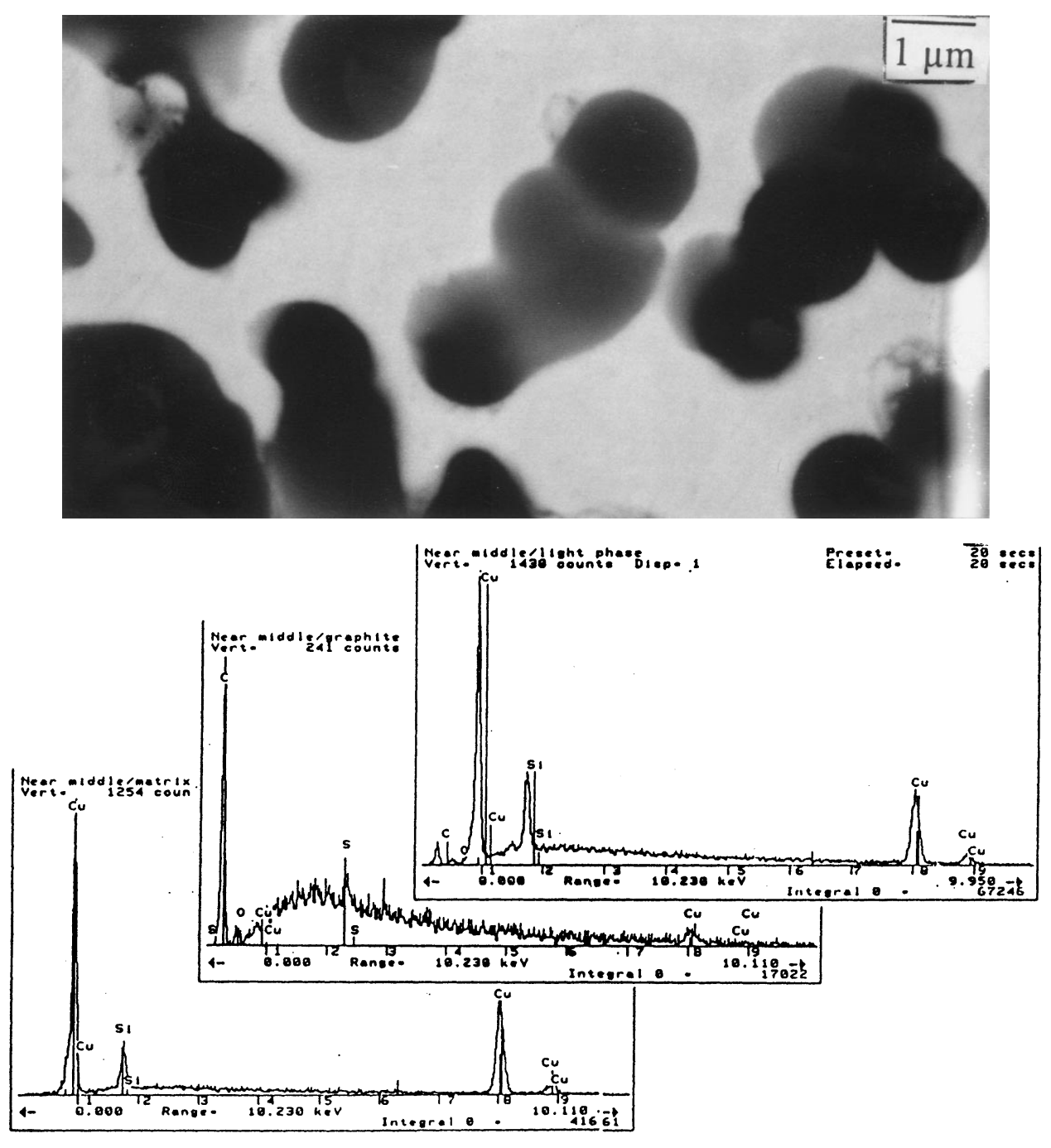

(a)

Fig. 5-High magnificatio SEM images and energy dispersive spectra. The leftmost spectra correspond to the alloy matrix: (a) the composite interior; and $(b)$ external chromium-rich reaction zone (shown in Fig. 4(c)).

rubbing surfaces, followed by their fracture and delamination, and is an indication of the adhesive wear. Cast-iron pins also showed similar delamination. The tribo-surface of the type 1 composite pin did not show such craters and delamination; instead, it was much smoother than that of the matrix alloy pin, and appeared to be almost covered by an occasionally broken thin fil at low stress, e.g., $22 \mathrm{MPa}$ (Figure 12(b)). The finel distributed, two-phase microstructure of the composite is clearly visible through this fil (Figure 12(b)). Nonconducting (copper oxide) debris particles, accumulating at the edges of the fil where it fractured, are responsible for the sharp bright contrast (typical region marked by an arrow). The extent of the fil breakage increased with increasing stress, typically shown in Figure 12(c) for $43 \mathrm{MPa}$. However, most of the pin surface was still covered with the same film the only difference being that the fil thickness was no longer uniform across the entire surface - the fil is thicker in region " $\mathrm{A}$ ", than in region " $\mathrm{B}$ " (Figure 12(c)).

An X-ray diffraction analysis showed that the debris from the type 1 composite pins wearing against the castiron plate were made of copper oxide and amorphous carbon (Figure 13). The $2 \theta$ angle of $25 \mathrm{deg}$, with $\mathrm{Cu} K_{\alpha}$ radi- ation for the amorphous phase, agrees with 26 deg reported for glassy carbon. ${ }^{[15]}$

\section{Role of Graphite in the Wear and Friction of Cu-6Si- 0.9Cr-Carbon Composites}

Figure 14 compares the variation in the coefficien of friction with the applied normal stress for (1) type 1 (copper alloy-amorphous carbon composite, shown as triangles), (2) type 2 (copper alloy- 0.2 graphite +0.8 amorphous carbon composite, shown as squares), (3) type 3 (copper alloy0.4 graphite +0.6 amorphous carbon composite, shown as circles), and (4) base alloy (shown as deltoids) wearing against cast-iron plate. The graphite-containing composites showed coefficien of friction values nearly identical to the abrasive wear of type 1 composite at low stress. However, at high stress, the coefficient were much larger than type 1. Their values at about $47 \mathrm{MPa}, 0.33$ for type 2 and 0.3 for type 3 , are nearly identical to that of the copper-matrix pins, 0.3 , indicating an adhesive wear. The transition from abrasive wear to the adhesive wear appears to occur at lower normal stress in type 2 composites, as compared with the type 3 composites. 

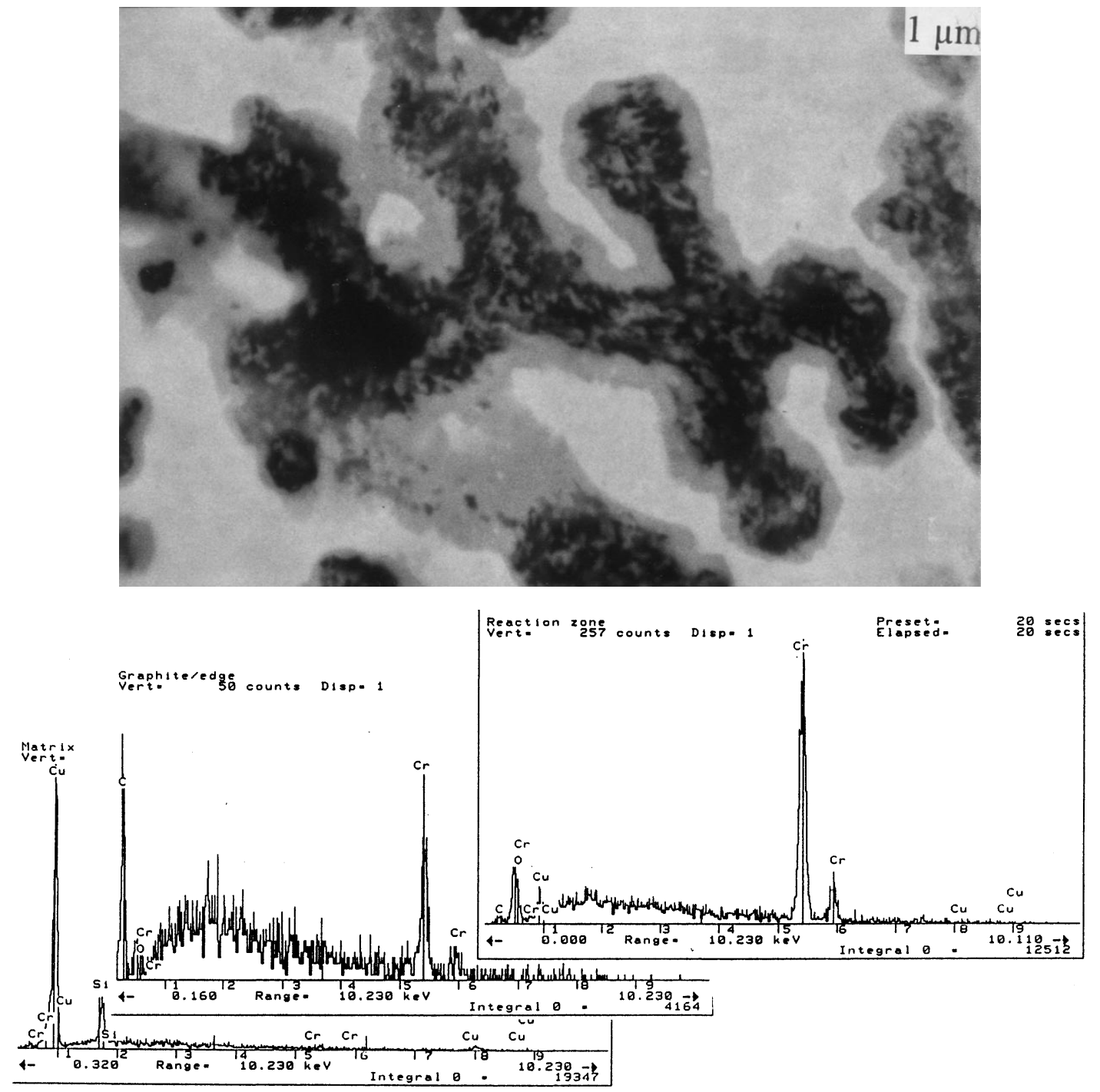

(b)

Fig. 5-Continued. High magnificatio SEM images and energy dispersive spectra. The leftmost spectra correspond to the alloy matrix: (a) the composite interior; and (b) external chromium-rich reaction zone (shown in Fig. 4(c)).

An examination of the load dependence of the fluctua tions in the steady-state coefficien of friction values for these composites shows that type 2 and type 3 composites both have small fluctuation at low stress (Figures 10(c) and (d)), similar to the abrasive wear of copper matrixamorphous carbon composite (Figure 10(b)). However, at high stress, the fluctuation are more severe (Figures 10(c)) and (d)) and compare with the adhesive wear of the copperalloy matrix pin (Figure 10(a)).

Figure 15 compares the dependence of the rates of wear on the applied normal stress for the three composites wearing against cast-iron plate. Triangles, squares, circles, and deltoids represent type 1 , type 2 , type 3 , and base alloy, respectively. The low wear rates of the graphite-containing composites at low stress are similar in magnitude to that caused by the abrasive wear of the type 1 composite containing only amorphous carbon. However, at the high loads, their wear rates are significantl larger than that of the type 1 composite, their value being similar to that due to the adhesive wear of the matrix alloy pin (Figure 11).
Figure 12(d) shows the typical appearance of the tribosurface after testing at $49 \mathrm{MPa}$ (type 2 composite). Similar to the adhesive tribo-surface of the matrix alloy pin (Figure 12(a)), there is extensive plastic deformation, grooving, and delamination in the metallic matrix portions of the composite microstructure. The matrix has flowe over the carbon-containing regions, the dark black specks below the deformed later of the matrix in Figure 12(d). The plastic flo of the metal masked the graphite and amorphous carbon particles, restricting their transfer to the tribo-surface. The debris particles tended to accumulate in the voids and at the fractured edges of such metallic layers. However, at low stress (22 $\mathrm{MPa}$ ), the thin carbon film described earlier for the abrasive wear of the type 1 composite pin (Figure 12(b)), was also observed for the two graphite-containing composites.

\section{DISCUSSION}

Wear and friction between two metals is believed to initiate by deformation and cutting of the softer asperities by 


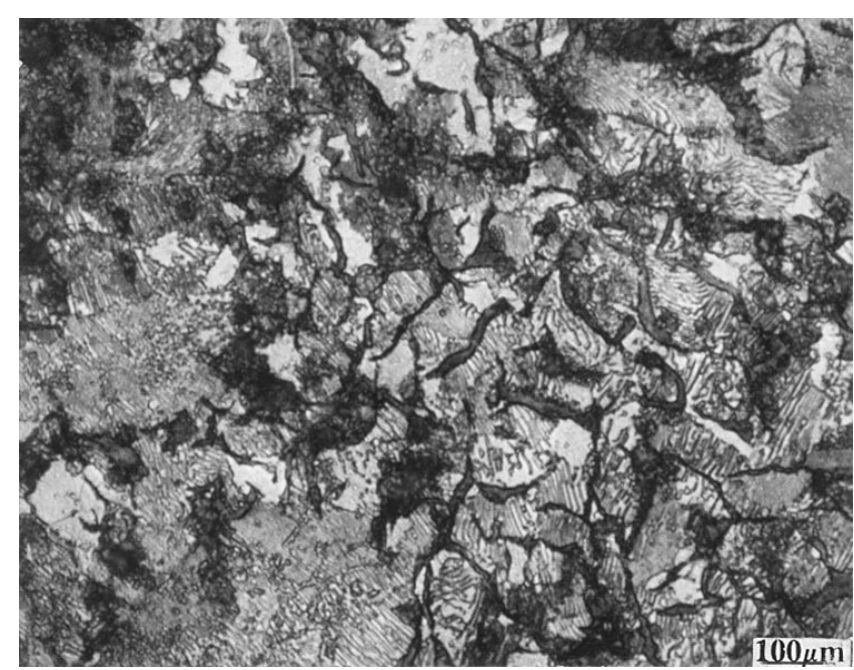

Fig. 6-Typical microstructure of the cast iron plate used in this study.

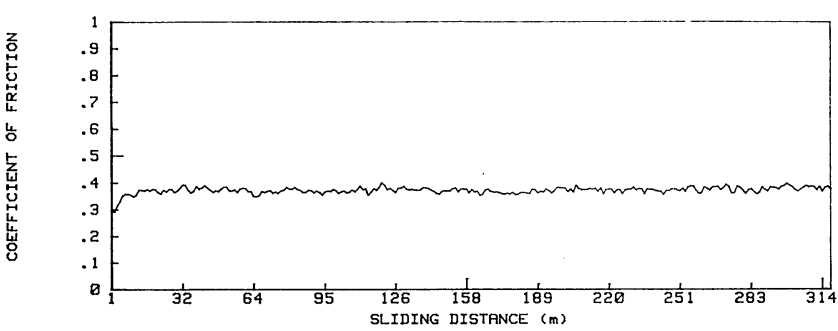

(a)

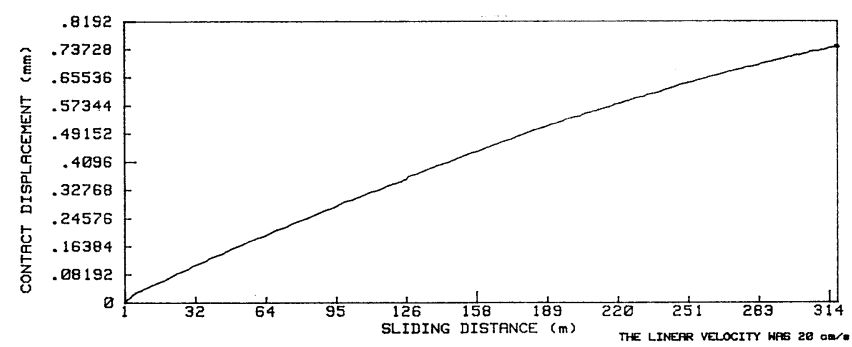

(b)

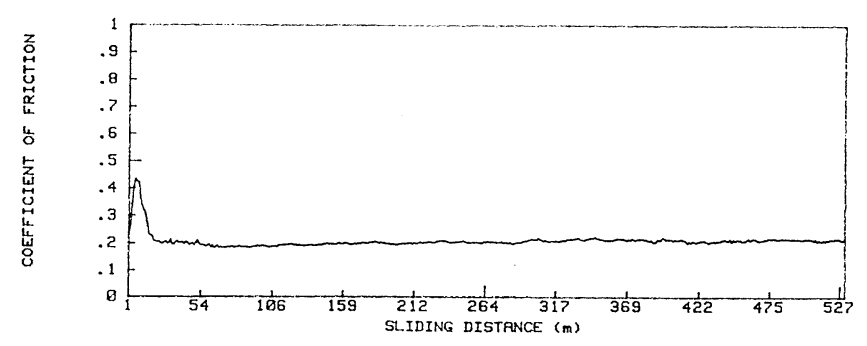

(c)

Fig. 7-Typical coefficien of friction and wear data as a function of the sliding distance (room temperature, linear speed $=20 \mathrm{~ms}^{-1}$ ). (a) Coefficien of friction for a matrix alloy $(\mathrm{Cu}-6 \mathrm{Si}-0.9 \mathrm{Cr})$ pin on cast iron plate (normal stress $=47 \mathrm{MPa}$ ). (b) Wear (contact displacement) for a matrix alloy $(\mathrm{Cu}-6 \mathrm{Si}-0.9 \mathrm{Cr})$ pin on cast iron plate (normal stress $=47$ MPa). (c) Coefficien of friction for a type 1 composite (copper alloy infiltrate into amorphous carbon preform) pin on cast iron plate (normal stress $=43 \mathrm{MPa}$ ).

the harder phase, resulting in an increased contact area. This is followed by adhesion between the two surfaces, plastic deformation and crack nucleation just below the contact surface, and the subsequent delamination. The in-

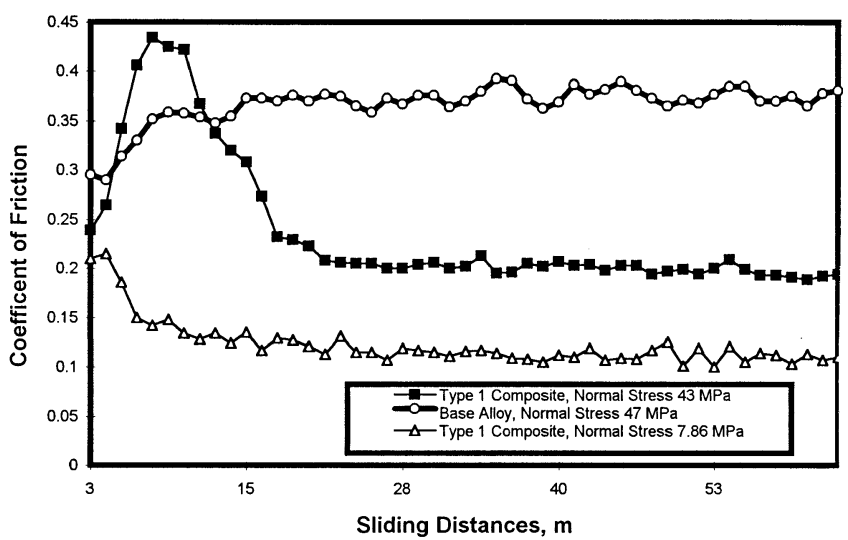

Fig. 8-Initial transient in the coefficien of friction during room temperature wear against cast iron plate.

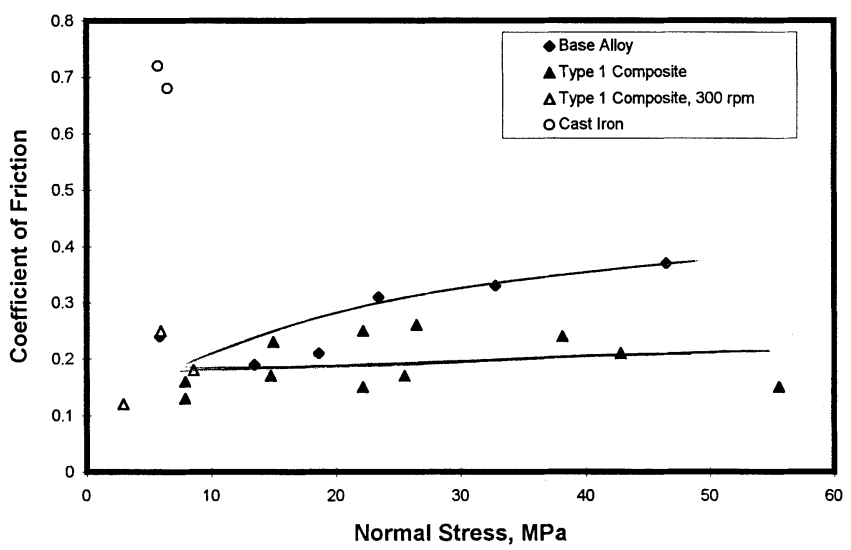

Fig. 9-Dependence of the steady-state coefficien of friction on the applied normal stress during room temperature wear against cast iron plate.

creased adhesion and delamination "ploughing" cause an increase in the wear and friction, and the thickness of the wear debris also increases. Finally, an equilibrium is reached between the rate of debris formation (by adhesion and delamination) and the rate of debris removal, which results in a steady-state wear and a constant coefficien of friction. The processes of adhesion and delamination, respectively, result in high and low shear stresses, and, therefore, cause fluctuation in the coefficien of friction. Severity of the adhesion and delamination increases with increasing normal stress, resulting in a higher coefficien of friction and also its larger fluctuation The experimental observations for the softer copper-alloy (168 VHN) pin wearing against harder cast-iron (231 VHN) plate, such as increasing coefficien of friction during the initial transient (Figure 8, shown as circles), severe fluctuation in the coefficien of friction (Figure 10(a)), and increase in the coefficien of friction with increasing normal stress on the pin (Figure 9), are all in agreement with the aforementioned expected behavior.

In the presence of a third body, such as graphite or amorphous carbon particles in the metal-matrix composites, the wear and friction process would become more complex. As pointed out by Rohatgi et al., ${ }^{[2]}$ the nature of the wear debris and its interaction with the two mating surfaces would be determined by factors such as size, shape, distribution, and volume fraction of the particles; the interfacial strength be- 


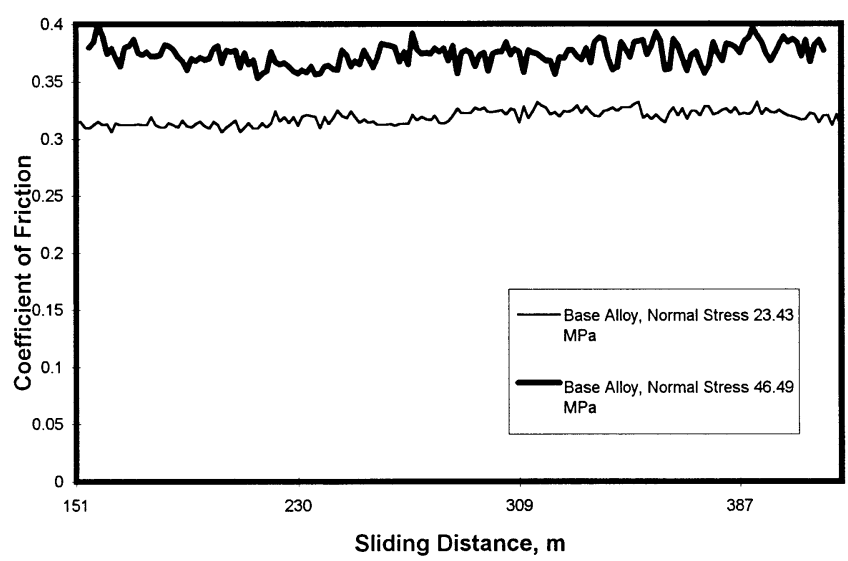

(a)

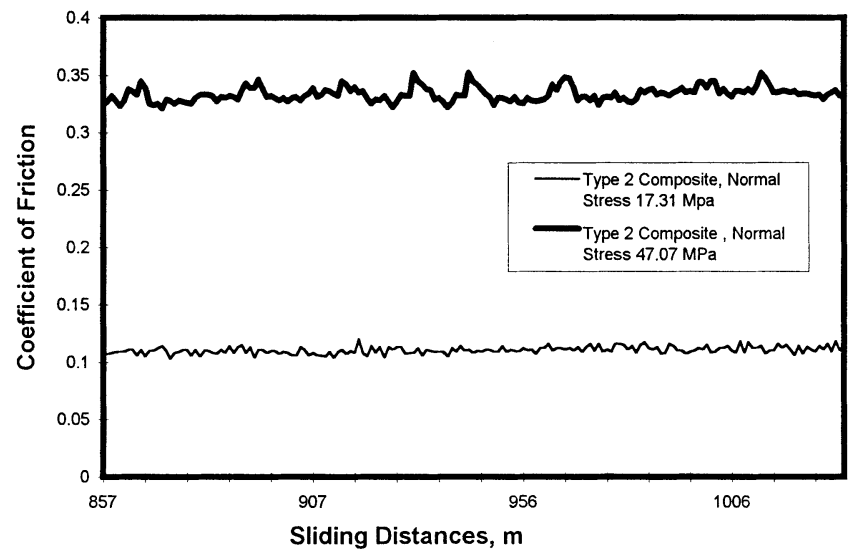

(c)

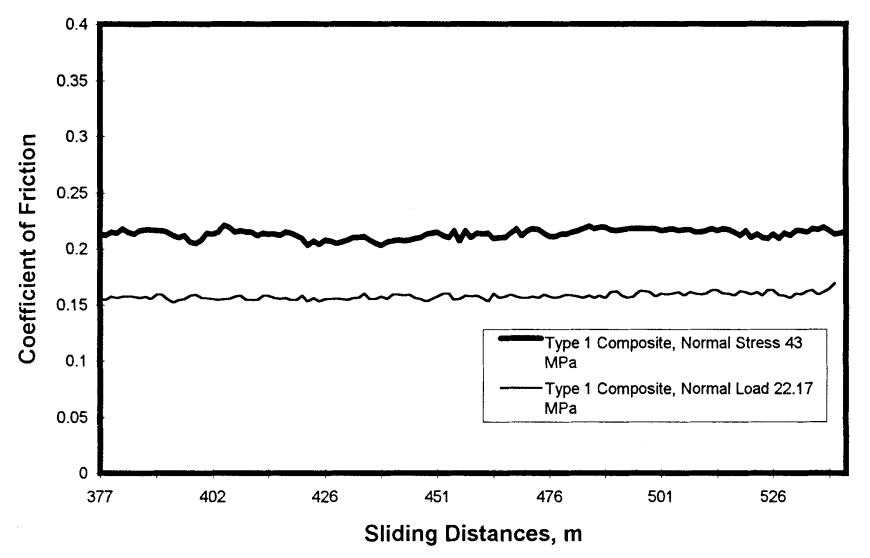

(b)

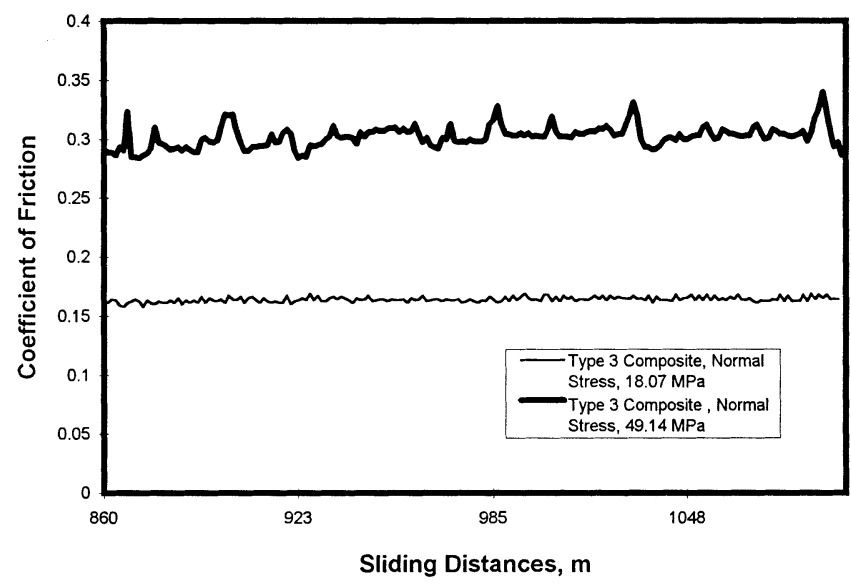

(d)

Fig. 10-Extent of fluctuatio in the steady-state coefficien of friction as a function of the normal stress on the pin: $(a)$ copper alloy pin; $(b)$ type 1 composite (amorphous carbon preform) pin; $(c)$ type 2 composite ( 20 pct graphite +80 pct amorphous carbon preform) pin; and $(d)$ type 3 composite (40 pct graphite +60 pct amorphous carbon preform) pin.

tween the matrix and the particles; the strength, ductility, and deformation behavior of the particles and the matrix; and the presence of defects (porosity). For the type 1 composite, which has finel distributed amorphous carbon in a copper-alloy matrix, two processes would compete during the initial transient in the coefficien of friction $v s$ sliding distance: (1) cutting and plastic deformation of the softer copper-alloy matrix asperities by the harder cast iron, which would increase the coefficien of friction, and (2) "bleed out" of the carbon particles onto the surface, which can create a carbon coating on the exposed metallic surfaces, decrease the likelihood of metallic adhesion, and result in decreased coefficien of friction. The wear debris would consist of carbon and the metallic matrix phase. However, the friction-induced hot surface temperature would tend to oxidize the matrix phase. The thickness of the debris layer, containing amorphous carbon and copper oxide (Figure 13), would slowly build up until a steady state is reached. With smaller applied normal stress on the pin, it would take longer to reach the steady state, as compared to the larger stresses (about $500 \mathrm{~m}$ at $8 \mathrm{MPa}$, vs only $20 \mathrm{~m}$ at $43 \mathrm{MPa}$ ) (Figure 8). It appears that at low stress, the carbon readily bleeds out on the surface before any significan cutting of the copper-alloy matrix constituent. This causes an initial decrease in the coefficien of friction. With increasing wear, the metal-to-metal contact surface area increases, and hence

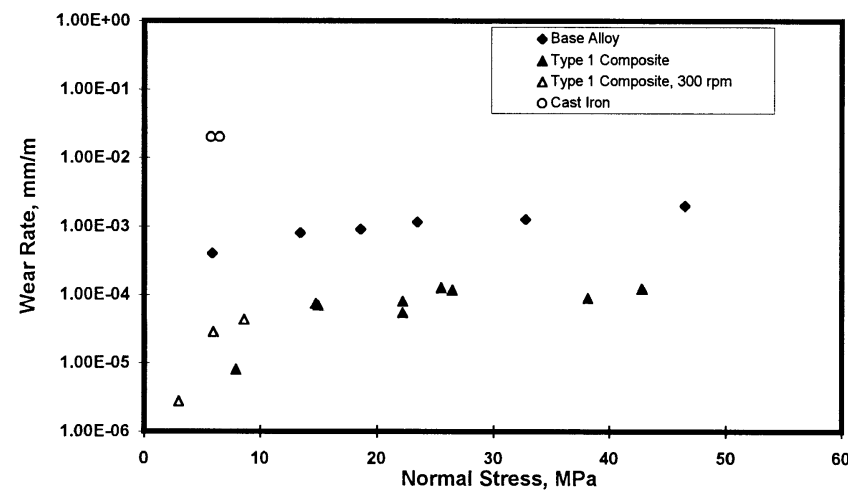

Fig. 11-Dependence of the wear rates on the applied normal stress during room temperature wear against cast iron plate.

the coefficien of friction begins to increase. Ultimately, a steady-state condition is reached, where the existing wear debris allows the pin surface to be continually covered by a thin coating of carbon (Figure 12(b)), resulting in an abrasive wear and a constant coefficien of friction of about 0.16. At high stress, the process of plastic deformation and cutting of the matrix asperities overpowers the extent of the carbon fil formation in the beginning, and results in an initial increase in the coefficien of friction (Figure 8, 


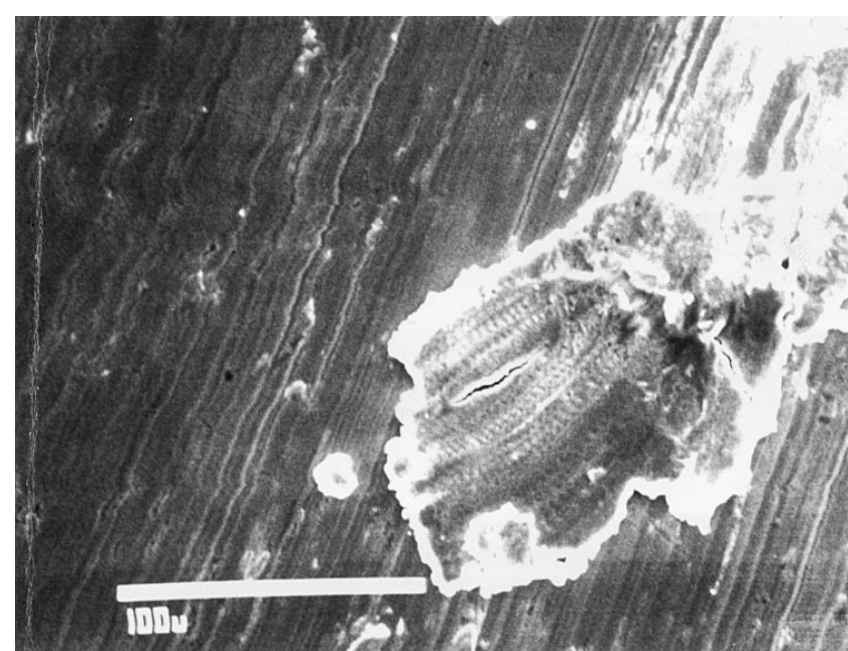

(a)

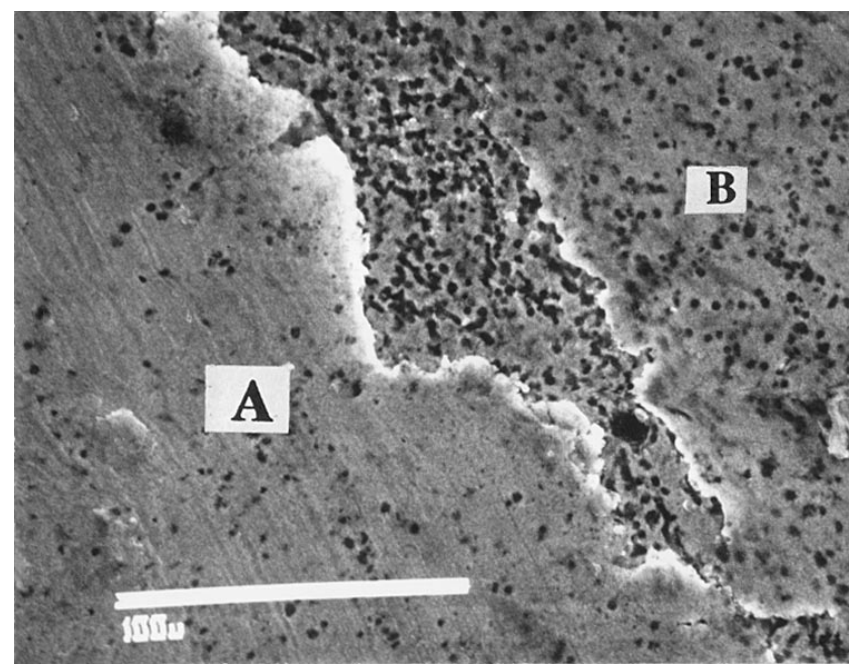

(c)

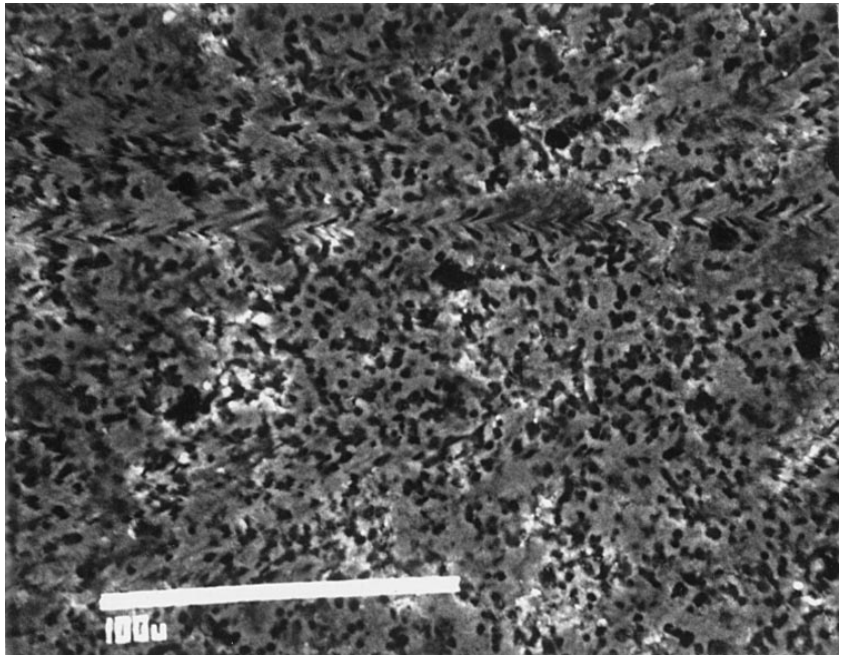

(b)

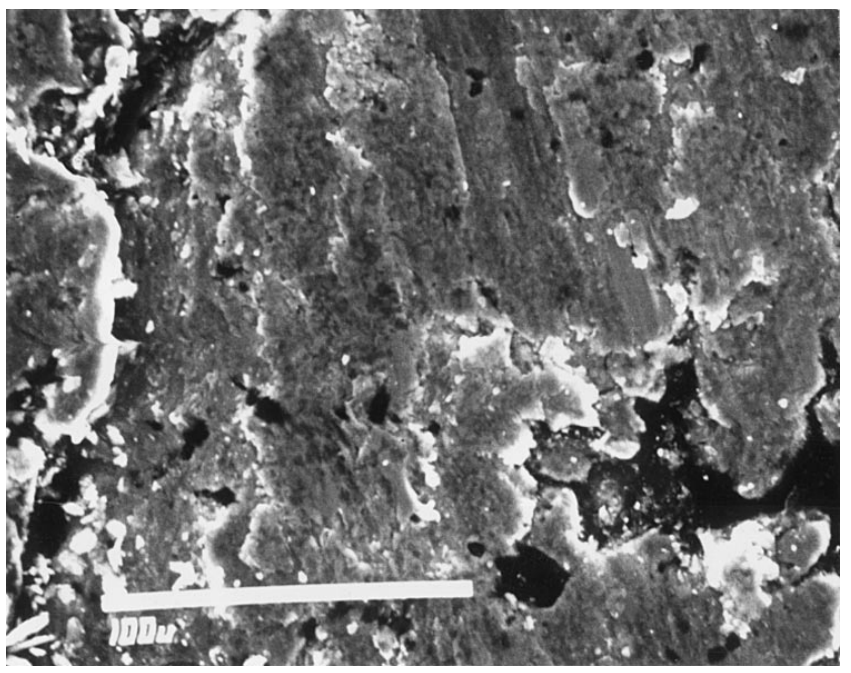

(d)

Fig. 12-Scanning electron micrograph of the pin surfaces after wear: $(a)$ matrix alloy pin (normal stress $=40 \mathrm{MPa}$ ); $(b)$ type 1 composite (amorphous carbon preform) pin (low normal stress, $22 \mathrm{MPa}$ ); $(c)$ type 1 composite (amorphous carbon preform) pin (high normal stress, $43 \mathrm{MPa}$ ); and $(d)$ type 2 composite (20 pet graphite +80 pct amorphous carbon preform) pin (high normal stress, $47 \mathrm{MPa}$ ).

shown as squares). With an increasing amount of carbon in the wear debris, the extent of carbon fil coverage on the tribo-surface increases, and the coefficien of friction begins to decrease. Ultimately, a steady state is reached, where the pin surface is continually covered by the thin carbon layer (Figure 12(c)), resulting in a constant coefficien of friction of about 0.21 . Unlike the alloy-matrix vs cast-iron wear, where the friction coefficien increases with increasing applied stress, the steady-state value of the friction coefficien is independent of the applied stress for the type 1 composite pins (Figure 9). This is because the pin surface gets covered by the same carbon fil for all the normal stresses examined in this study (Figure 12); only the variation in the fil thickness across the specimen surface is more at high stress. This variation is produced because higher normal stress leads to the formation of larger fil thickness, and layers within these film tend to shear off from each other (Figure 12(c)).

The integrity of the carbon fil during sliding wear of the composite is expected to depend on several factors, such as the size and extent of porosity and the size of the metallic and carbon constituents. Porosities in the composite, when exposed to the wearing surface, would make the process of ploughing and delamination easier and tend to break the carbon film The integrity of the carbon fil is easier to maintain in the presence of a very fin size and uniform distribution of carbon and metallic phases, because as the metallic constituent deforms and flow (exposing a fresh metallic surface that can cause adhesion), the carbon is right there to create the next thin carbon layer. This is not likely for a composite where the metallic constituents are large and the spacings between the carbon particles are large. Such a microstructure would, therefore, cause more adhesive wear, yielding higher coefficient of friction and their larger fluctuations especially at higher normal stress where plastic deformation and fracture of the matrix phase are more likely. The type 2 and type 3 composites, therefore, despite the presence of a significan amount of soft graphitic carbon, show higher coefficient of friction at large stress (47 MPa), as compared to type 1 (Figure 14), because they have significan porosity (9 pct $50 \mu \mathrm{m}$ average size) and their metallic constituents are much larger (Figure 16) 


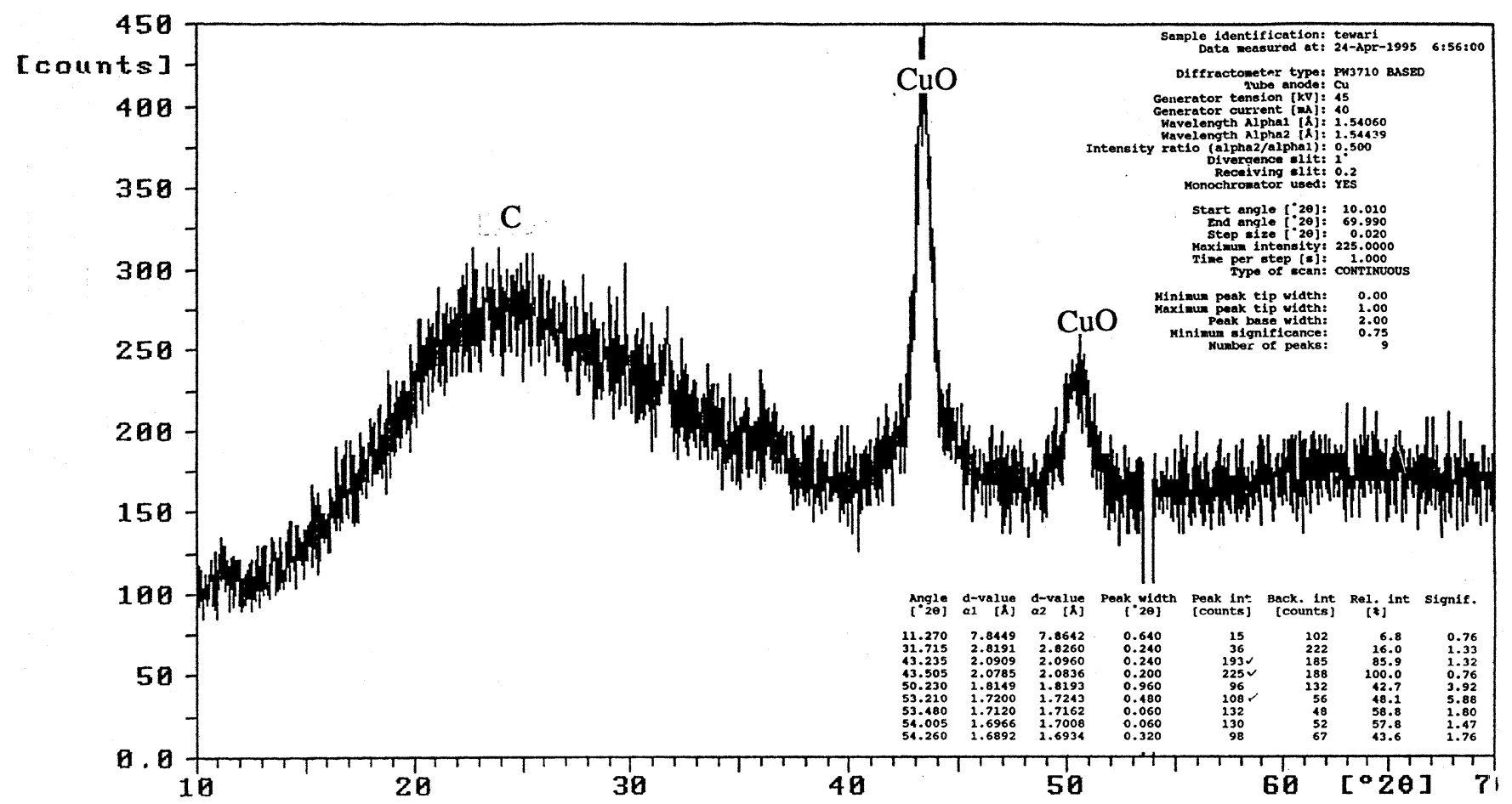

Fig. 13-X-ray diffraction analysis of debris generated during wear of type 1 composite pin on cast iron plate.

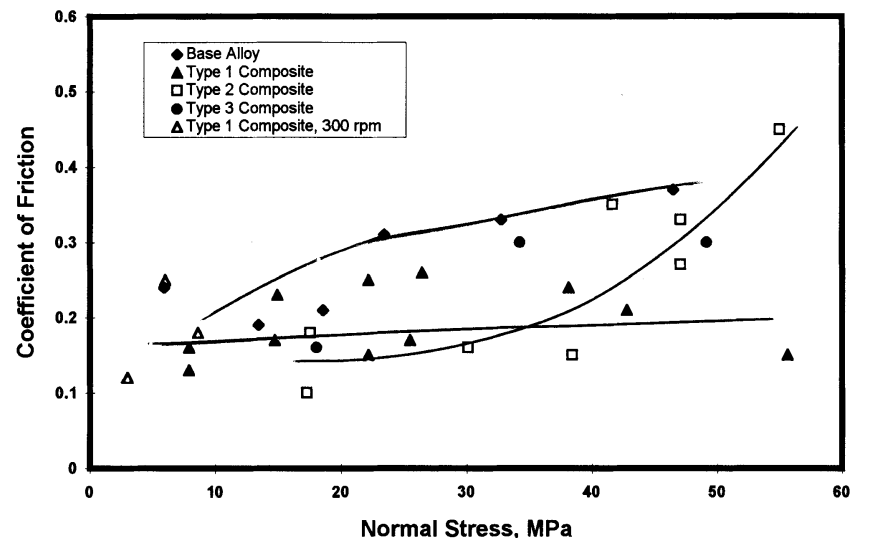

Fig. 14-Variation in the coefficien of friction with the applied stress during room temperature wear against cast iron plate, influenc of graphite content in the composite.

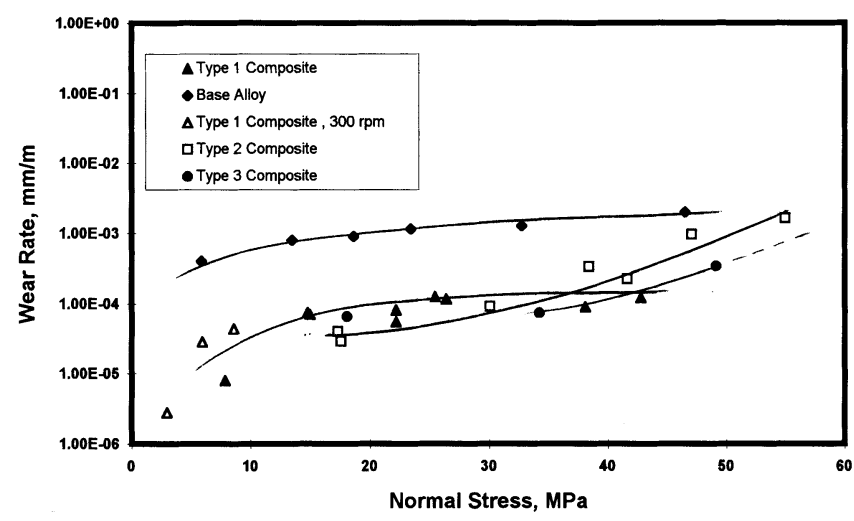

Fig. 15-Dependence of the rate of wear on the applied stress during room temperature wear against cast iron plate, influenc of graphite content in the composite.
(28 and $22 \mu \mathrm{m} v s 10 \mu \mathrm{m}$ for the type 1 composite), causing adhesive wear. The adhesive wear is also reflecte by the large fluctuation in their coefficien of friction (Figure 10), and their high wear rates at the high loads (Figure 15). At low stress (17 MPa), the type 2 and type 3 composites yield coefficien of friction values similar to the abrasive wear of the type 1 composite (Figure 14), because of the presence of the thin carbon fil on their tribo-surface. The transition from the abrasive to the adhesive wear, observed in the graphite containing type 2 and type 3 composites, was not seen in the type 1 composite, because the uniform and fin distribution of the two-phase copper-alloy matrix and amorphous carbon promoted the formation of the thin carbon fil and did not allow adhesion to occur.

\section{CONCLUSIONS}

The following conclusions can be drawn from this wear and friction study on pressure-infiltratio cast $\mathrm{Cu}-\mathrm{C}$-based metal-matrix ceramic composites. The wear resistance of the composite is significantl improved, as compared with the base alloy. Contrary to the normally expected behavior, the addition of graphite to the amorphous carbon does not reduce the friction coefficient especially at high loads. The wear and friction behavior of the composites is very sensitive to the size and distribution of the microstructural constituents.

\section{ACKNOWLEDGMENTS}

Appreciation is expressed to J. Smith, C. Palda, and B. Hanyaloglu for providing assistance and to NASA-Lewis Research Center and UNIDO for partially supporting this research. We are grateful to Professor S. Nourbaksh (New 
York Polytechnick Institute) for sharing the design of his pressure caster with us.

\section{REFERENCES}

1. C.Z. Zuben: J. Met., 1992, vol. 44 (7), p. 15.

2. P.K. Rohatgi, S. Ray, and Y. Liu: Int. Mater. Rev., 1992, vol. 37, pp. 129-49.

3. M. Suwa, K. Komuro, and K. Soeno: J. Jpn. Inst. Met., 1976, vol. 40 , p. 1074

4. D.L. McDanels and J.O. Diaz: NASA TM-102328, 1989.

5. Y. Tsuya: J. Jpn. Inst. Composites, 1985, vol. 11, p. 127.

6. P.K. Rohatgi: Metals Handbook, vol. 9, Casting, ASM INTERNATIONAL, Materials Park, OH, 1990.
7. L.J. Masur, A. Mortensen, J.A. Cornie, and M.C. Flemings: Metall. Trans. A, 1989, vol. 20A, pp. 2549-57.

8. A. Mortensen and I. Jin: Int. Mater. Rev., 1992 vol. 37, p. 101.

9. R.A. Burton and R.G. Burton: Trans. ASME, 1990, vol. 112, pp. 6872 .

10. J.K. Lancaster: ASLE Trans., 1975, vol. 20 (1), pp. 430-54.

11. E.E. Hucke: U.S. Patent 3459421, 1975.

12. M. Singh and D.R. Behrendt: NASA-TM-105860, NASA-Lewis Research Center, Cleveland, OH, 1992.

13. D. Mortimer and M. Nicholas: J. Mater. Sci., 1970, vol. 5, pp. 14955.

14. A.R. Nesarikar, S.N. Tewari, and E.E. Graham: Mater. Sci. Eng., 1991, vol. A147, pp. 191-99.

15. R. Burton and A. Burton: ASM INTERNATIONAL Proc., Oak Ridge, TN, May 1-3, 1990, ASM INTERNATIONAL, Materials Park, OH, 1990, pp. 309-14. 